\title{
Mussel processing wastewater: a low-cost substrate for the production of astaxanthin by Xanthophyllomyces dendrorhous
}

\author{
Isabel Rodríguez Amado ${ }^{1,2^{*}}$ (1) and José Antonio Vázquez
}

\begin{abstract}
Background: The use of astaxanthin in different industries such as the chemical, pharmaceutical, food, animal feed and cosmetic has been receiving increasing attention in recent years. Natural supplies of the pigment include crustacean by-products, algal, and microbial cultivation, being the yeast Xanthophyllomyces dendrorhous together with the alga Haematococcus pluvialis the most promising microorganisms for this bioproduction. Different vegetable by-products of the food industry have been explored so far as low-cost substrates for the production of astaxanthin by $X$. dendrorhous. This study focuses for the first time on the use of a low-cost formulated medium from a marine byproduct, mussel-processing wastewater, for the production of astaxanthin by the yeast $X$. dendrorhous.

Results: The yeast was able to grow in non-saccharified mussel broth, revealing the ability of the microorganism to hydrolyze glycogen. However, partial glycogen saccharification with a-amylase was needed for astaxanthin biosynthesis, obtaining maximal productions of $22.5-26.0 \mathrm{mg} / \mathrm{L}$ towards the end of the culture and coinciding with yeast highest amylolytic activity. Cultivations in totally-saccharified media revealed an increase in maximal cell concentrations and a decrease in maximal growth rates and astaxanthin production with increasing glucose initial concentration.

Conclusions: Astaxanthin production was higher in partially-saccharified mussel-processing waste than in synthetic medium (yeast peptone dextrose) containing glucose as carbon source $(13 \mathrm{mg} / \mathrm{L})$, suggesting this by-product is a promising nutritive medium for astaxanthin production. The use of this effluent also contributes towards the recycling and depuration of this highly pollutant effluent.
\end{abstract}

Keywords: Astaxanthin, Yeast, Antioxidant, Glycogen, Fermentation, Aquaculture, Amylolytic activity, Marine by-products

\section{Background}

Astaxanthin (3,3-dihydroxy- $\beta, \beta$-carotene- 4,4 dione) is a ketocarotene widely used in aquaculture as a feed additive for the pigmentation of salmonid meat, and crustacean shells [1]. Astaxanthin has been reported to inhibit lipid peroxidation and low-density lipoprotein (LDL) oxidation [2] in rats and mice due to its potent antioxidant

\footnotetext{
*Correspondence: sabelara@uvigo.es; sabelara@iim.csic.es

${ }^{1}$ Grupo de Reciclado y Valorización de Residuos (REVAL), Instituto de Investigacións Mariñas (IIM-CSIC), R/Eduardo Cabello 6, 36208 Vigo, Spain Full list of author information is available at the end of the article
}

activity. Recent studies suggest astaxanthin could improve the serum lipid profile [3], and enhance the cytotoxic activity of natural killer cells [4]. As a consequence of these potential benefits for human health, the market for astaxanthin as a dietary supplement in human diets has increased in the last years [5].

Several natural sources of astaxanthin have been explored so far owing to its increasing level of demand for novel applications in the food, pharmaceutical and cosmetic industries [6]. Natural supplies of the pigment include shrimp [7], crawfish by-products [8], crustacean wastewaters $[9,10]$ 
and microbial cultivation [11]. The synthesis of astaxanthin by several yeast species belonging to the genera Rhodotorula and Phaffia, and by the microalgae Chlorella zofingiensis, Chlorococcum sp. and Haematococcus pluvialis has led to consider these microorganisms as potential pigment sources [5]. Among them, Xanthophyllomyces dendrorhous (former Phaffia rhodozyma), and H. pluvialis are to date the most promising microorganisms, being the alga the largest producer of the pigment. In fact, astaxanthin for aquaculture and human dietary supplements are produced from $H$. pluvialis at industrial scale [12].

Although astaxanthin production from yeasts is lower than algae [13], the former is preferred due to higher growth rates and easier cultivation conditions [14] that might decrease the production time at industrial scale [1]. Different agri-food wastes such as cassava starch [15], corn fiber [16], molasses [17], and eucalyptus globules wood [18] were explored as astaxanthin low-cost sources. However to the best of our knowledge, marine by-products have not yet been investigated for the cultivation of $X$. dendrorhous in spite of their high content of nutritive compounds. Mussel processing wastewater (MPW) is a residual effluent from the canning industry rich in glycogen and proteins [19]. This by-product was successfully utilized to produce amylase [20], bacteriocins [21], and hyaluronic acid [22] by different microorganisms.

The ability to degrade starch is not widespread in yeast, however, $X$. dendrorhous produces a $\beta$-amylase whose synthesis is induced by starch and maltose [23]. Also shows extracellular exo-acting enzymatic activity able to cleave $\alpha$ 1-4 glycosidic bonds from soluble starch, maltose, and maltooligosaccharides [24]. Despite its unusual substrate specificity, the enzyme was classified as $\alpha$-glucosidase due the formation of glucose, and not maltose or maltotriose, as the final product of the hydrolytic reaction. Those enzymes, with potential interesting industrial applications [23, 25], would enable the use of amylaceous substrates as carbon sources for astaxanthin production by $X$. dendrorhous.

In the present study, we assessed the suitability of concentrated and partially or totally-saccharified mussel processing wastewater for the production of astaxanthin in submerged culture of $X$. dendrorhous.

\section{Results and discussion}

\section{Selection of astaxanthin-producing strain}

Astaxanthin-producing strains CECT 1690, CECT 11028 and ATCC 74219 were screened in Yeast Peptone Dextrose (YPD) and Yeast Complex Medium (YCM, Table 1). All three strains were able to metabolize both glucose and starch, confirming $X$. dendrorhous amylolytic activity. Growth and astaxanthin production in YCM were lower due to incomplete sugar consumption (Fig. 1). The microorganism only consumed around $50 \%$ starch of the culture medium after 4 days of culture. $X$. dendrorhous showed a similar trend of starch consumption when grown in MM

Table 1 Composition of the culture media used in the present study (g/L)

\begin{tabular}{|c|c|c|c|c|c|c|}
\hline & YPD & YCM & MS & PSM & PSMS & TSMS \\
\hline Glucose & 20.00 & - & - & 50 & 50 & 20/40/80/100 \\
\hline Total sugars & - & - & 100 & 100 & 100 & 20/40/80/100 \\
\hline Soluble starch & - & 5.00 & - & - & - & - \\
\hline Bactopeptone & 20.00 & - & - & - & - & - \\
\hline Yeast extract & 10.00 & 2.50 & 10.00 & 10.00 & 10.00 & 10.00 \\
\hline Malt extract & - & 2.50 & - & - & - & - \\
\hline$\left(\mathrm{NH}_{4}\right)_{2} \mathrm{SO}_{4}$ & - & - & 5.00 & 5.00 & 5.00 & 5.00 \\
\hline $\mathrm{KH}_{2} \mathrm{PO}_{4}$ & - & 1.00 & 2.00 & 2.00 & 2.00 & 2.00 \\
\hline $\mathrm{MgSO}_{4}$ & - & 0.50 & 1.00 & - & 1.00 & 1.00 \\
\hline $\mathrm{K}_{2} \mathrm{HPO}_{4}$ & - & - & 0.40 & 0.40 & 0.40 & 0.40 \\
\hline $\mathrm{CaCl}_{2}$ & - & 0.35 & 0.20 & - & 0.20 & 0.20 \\
\hline $\mathrm{ZnSO}_{4}$ & - & - & 0.03 & - & 0.03 & 0.03 \\
\hline $\mathrm{FeNH}_{4}\left(\mathrm{SO}_{4}\right)_{2}$ & - & - & 0.01 & - & 0.01 & 0.01 \\
\hline $\mathrm{CuSO}_{4}$ & - & - & 0.002 & - & 0.002 & 0.002 \\
\hline $\mathrm{NH}_{4} \mathrm{Cl}$ & - & 2.00 & - & - & - & - \\
\hline Vitamin premix (\% v/v) & - & - & 5 & - & 5 & 5 \\
\hline $\mathrm{C} / \mathrm{N}$ ratio & 6.33 & 10.6 & 35.7 & 35.3 & 35.5 & $12.0 / 20.5 / 33.7 / 38.1$ \\
\hline
\end{tabular}

The vitamin premix contains $2 \mathrm{~g} / \mathrm{L}$ inositol, $1 \mathrm{~g} / \mathrm{L}$ pyridoxine, $0.2 \mathrm{~g} / \mathrm{L}$ calcium pantothenate, $40 \mathrm{mg} / \mathrm{L}$ thiamine and $2 \mathrm{mg} / \mathrm{L}$ biotin

YPD yeast peptone dextrose, YCM yeast complet medium, MS mussel supplemented medium, PSM partially saccharified mussel medium, PSMS partially saccharified mussel supplemented medium, TSMS totally saccharified mussel supplemented medium 


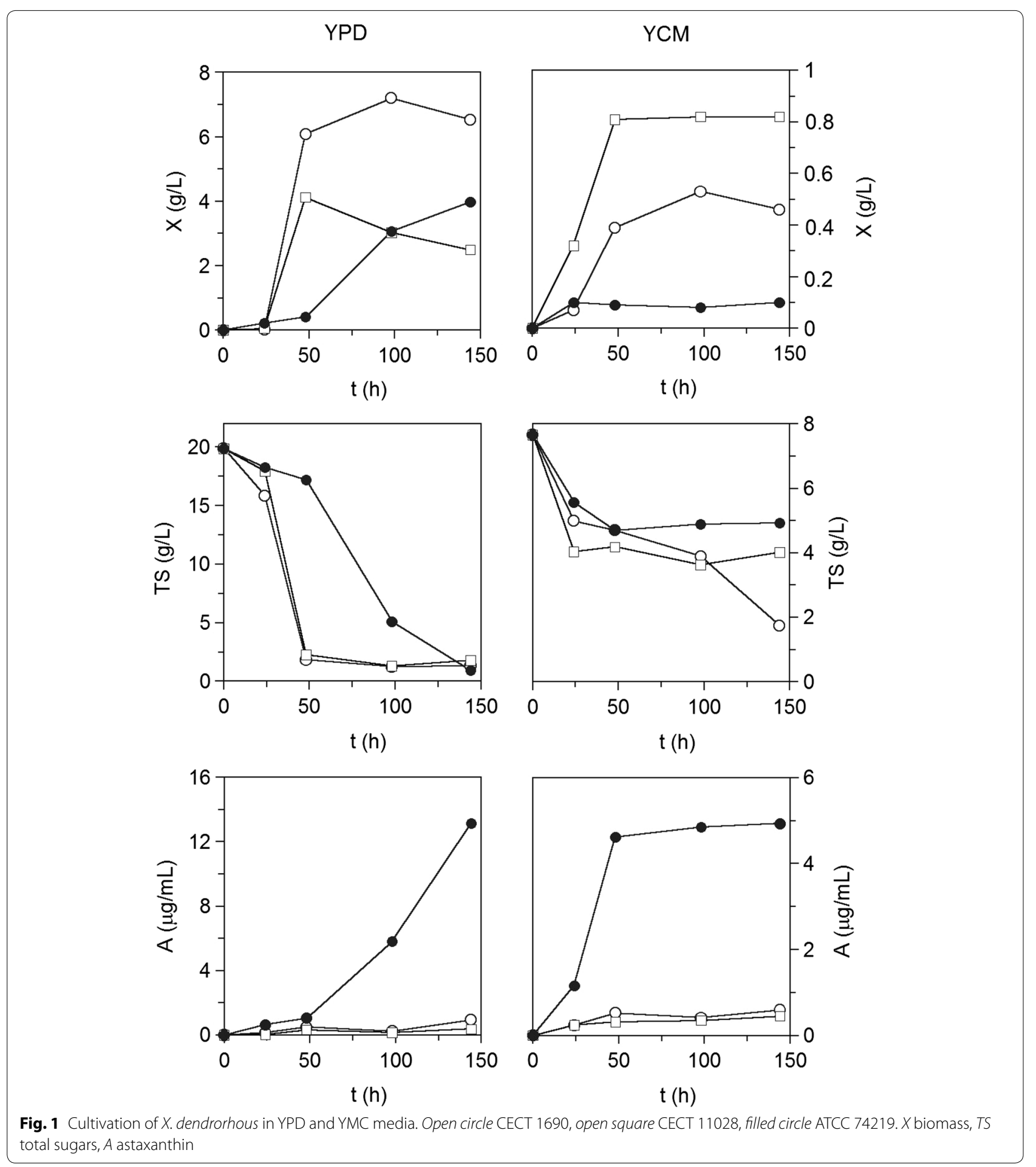

( $0.7 \%$ yeast nitrogen base) medium supplemented with $1 \%$ starch as a carbon source [24]. These authors found glucose was the only product from hydrolytic reactions, pointing to yeast $\alpha$-glucosidase activity. Díaz et al. [23] also found yeast amylolytic activity in SD (0.7 \% yeast nitrogen base without amino acids) medium containing $1 \%$ starch. However, they found the enzyme was a $\beta$-amylase, due to the absence of glucose as the final product of the hydrolytic activity. 
Astaxanthin productions were higher for strain ATCC 74219 irrespective of the carbon source. ATCC 74219 productions were fivefold to more than tenfold higher in starch and glucose containing media, respectively compared to strains CECT 1690 and CECT 11028 (Fig. 1). Astaxanthin biosynthesis was mainly associated with the second half of the culture cycle (exponential and stationary phase), reaching maximum productions $(13 \mathrm{mg} / \mathrm{L})$ at the end of the culture (Fig. 1). Carotenoid production by $X$. dendrorhous typically shows a pattern of a secondary metabolite [26]. While astaxanthin production in ATCC 74219 was the highest among the three $X$. dendrorhous strains, biomass production was the lowest. These results agree with the greater yields of astaxanthin on biomass $\left(Y_{A / X}\right)$ compared to CECT 1690 and CECT 11028 strains (Table 2). Uncoupling of biomass and astaxanthin production is usually attributed to different cell nutritional requirements, where a low $\mathrm{C} / \mathrm{N}$ ratio improves cell biosynthesis while a high $\mathrm{C} / \mathrm{N}$ ratio enhances astaxanthin production [27, 28]. Astaxanthin yields were, in fact, higher in the culture medium with the highest $\mathrm{C} / \mathrm{N}$ ratio (Table 1).

According to these results, the strain ATCC 74219 was selected for further investigation due to its higher astaxanthin production and to its ability to grow in starchy substrates.

\section{Selection of astaxanthin extraction method}

The most effective method of carotenoid extraction was cell disruption with dimethylsulfoxide (DMSO) followed by autoclaving in acidic conditions, mechanical abrasion and enzymatic treatment (Fig. 2). Disruption of yeast cells using DMSO improved astaxanthin recovery according to previous papers [29].

In general, astaxanthin was more effectively released from fresh cells, and a second extraction with hexane: ethylacetate did not improve astaxanthin recovery (Fig. 2). Cell disruption was more effective on dried cells, as observed by Da Fonseca et al. [29] using a similar biomass/DMSO ratio. Astaxanthin recovery was maximal $(6 \mathrm{mg} / \mathrm{L})$ from fresh cells and high biomass/DMSO ratio, and dried biomass using low biomass/DMSO (Fig. 2). When using high-density cell $\left(>2 \times 10^{8}\right.$ cells $)$ cultures [30], such as those of the present work $\left(3 \times 10^{8}\right.$ cells $)$, the extraction may be incomplete. This lower recovery is because the volume of the chemical disruptor is too low, leading to the formation of a thick insoluble pigmented interface keeping the carotenoids [30]. The maximum astaxanthin specific concentration obtained in this study ( $2 \mathrm{mg} / \mathrm{g}$ ) was higher compared to the $332-786 \mu \mathrm{g} / \mathrm{g}$ obtained by Sedmak et al. [30] from various strains of $X$. dendrorhous using the same DMSO extraction method. Da Fonseca et al. [29] reported slightly higher astaxanthin recoveries $(2.5 \mathrm{mg} / \mathrm{g})$ from dried and freeze-dried yeast cells after several extraction cycles (2-4) with DMSO.

According to these results, the method of astaxanthin extraction selected for further pigment recovery was DMSO $(\times 2)$ applied to fresh yeast cells, avoiding the need for drying pretreatment.

\section{Culture of Xanthophyllomyces dendrorhous in partially-saccharified mussel wastewater}

Three nutritive broths were formulated using autoclaved mussel-processing waste as culture media for astaxanthin production by ATCC 74219. The use of high molecular weight polysaccharides as carbon source requires the synthesis of yeast extracellular amylases, which could be a restrictive factor for the utilization of an effluent containing glycogen as the carbon source [31]. A partial saccharification using $\alpha$-amylase from Aspergillus oryzae was carried out under previously optimized conditions [31], leading to a $51 \%$ of hydrolysis referred to the level of reducing sugars. Salts and vitamins reported to improve carotenoid production were added to culture media containing non-saccharified (MS) or partially-saccharified (PSMS) mussel processing waste. A bibliographic review revealed formulations containing inorganic nitrogen and phosphorus sources $\left(\left(\mathrm{NH}_{4}\right)_{2} \mathrm{SO}_{4}, \mathrm{~K}_{2} \mathrm{HPO}_{4}\right.$, and $\left.\mathrm{KH}_{2} \mathrm{PO}_{4}\right)$ and mesonutrients such as $\mathrm{MgSO}_{4}$ and $\mathrm{CaCl}_{2}$ lead to high astaxanthin productions $(>5000 \mu \mathrm{g} / \mathrm{g})$ in semi-industrial [26], and industrial [27] submerged cultures. According to the latter, including micronutrients $\left(\mathrm{FeNH}_{4}\left(\mathrm{SO}_{4}\right)_{2}\right.$, $\mathrm{CuSO}_{4}$ and $\mathrm{ZnSO}_{4}$ ) and traces of vitamins (inositol, pyridoxine, calcium pantothenate, thiamine, and biotin) is also required to maximize the yields of astaxanthin production. A culture medium containing partially-saccharified mussel-processing waste without supplementation (PSM) was also tested to study whether the salts and vitamins enhanced astaxanthin production. The composition of MS, PSM and PSMS is shown in Table 1.

$X$. dendrorhous was able to grow in all culture media, including the non-saccharified MS broth. The ability to use glycogen as a carbon source is a remarkable feature of the yeast that expands the information available about the ability of $X$. dendrorhous to metabolize polysaccharides. As mentioned above, the yeast ability to hydrolyze starch has been widely reported [23, 24]. However, to the best of our knowledge, this is the first report of glycogen hydrolysis by this microorganism.

Typical diauxic growth curves showing an initial phase of rapid growth followed by a lag phase after $36 \mathrm{~h}$ of culture, and reaching similar final biomass productions were observed (Fig. 3). Diauxic growth profiles evidenced a different pattern of sugar consumption throughout $X$. dendrorhous cultivation (Fig. 3). Mussel processing waste was partially hydrolysed with $\alpha$-amylase, an enzyme exhibiting 
Table 2 Yields of $X$. dendrorhous cultivation in YPD and YMC culture media

\begin{tabular}{lcll}
\hline & $Y_{A / X}(\mathbf{m g} / \mathbf{g})$ & $Y_{A / T S}(\mathbf{m g} / \mathbf{g})$ & $Y_{X / T S}(\mathbf{g} / \mathbf{g})$ \\
\hline YPD & & & \\
CECT1690 & 0.143 & 0.050 & 0.352 \\
CECT11028 & 0.148 & 0.020 & 0.138 \\
ATCC 74219 & 3.312 & 0.693 & 0.209 \\
YCM & & & \\
CECT1690 & 1.263 & 0.099 & 0.078 \\
CECT11028 & 0.554 & 0.124 & 0.224 \\
ATCC 74219 & 48.70 & 1.806 & 0.037 \\
\hline
\end{tabular}

$Y_{A / X}$ yield of astaxanthin production on biomass, $Y_{A / T S}$ yield of astaxanthin production on sugars consumed, $Y_{X T S}$ yield of biomass on sugars consumed

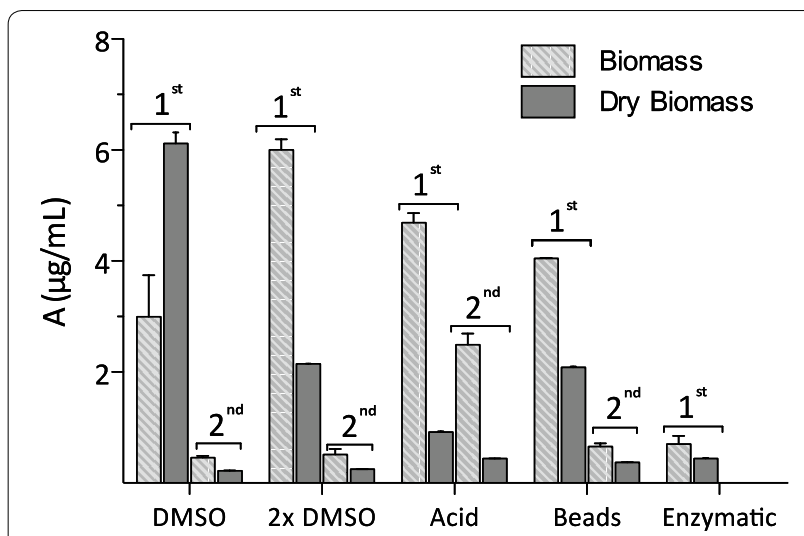

Fig. 2 Astaxanthin recovery from $X$. dendrorhous ATCC 74219 using different cell disruption methods applied to fresh and dried yeast cells. First and second extractions were carried out in hexane:ethylacetate (1:1). Mean values and standard deviations from duplicate samples are shown

endo-acting activity that cleaves 1,4-D-glucosidic linkages between adjacent glucose units in long chain polysaccharides, like starch and glycogen, and yielding maltose as a final product. Furthermore, HPLC analysis of the culture media revealed very low initial glucose concentrations $(3-4 \mathrm{~g} / \mathrm{L})$ in PSM and PSMS, and no glucose in MS medium. The low glucose content confirms expected $\alpha$-amylase activity in a rich glycogen substrate and suggests most of initial reducing sugars, up to $50 \mathrm{~g} / \mathrm{L}$ in partially-saccharified media (Fig. 1), are likely to be maltose and maltooligosaccharides. Diauxic growth was then due to a rapid consumption of di- and oligosaccharides hydrolyzed by $X$. dendrorhous extracellular $\alpha$-glucosidase [24], according to the slight increase in sugar concentration observed (Fig. 3). Then a lag phase (36-96 h) in sugar consumption followed by a steep uptake during the last $48 \mathrm{~h}$ of culture (144-196 h) occurred. During this lag phase, yeast $\beta$-amylase was most likely induced by maltose [23], according with the observed increase in the extracellular amylolytic activity, which reached the highest activity levels $(0.4 \mathrm{EU} / \mathrm{mL})$ in the final stationary phase (Fig. 4). Amylolytic activity in glycogen-containing culture broth (MS) was lower and slower induced (Fig. 4). Low glycogen hydrolysis lead to lower sugar consumption compared to PSM and PSMS, and to higher yields on biomass produced in non-saccharified medium (Table 3). So, it is reasonable to assume cell biosynthesis in MS was due to protein intake (Fig. 3) that is also a carbon source, and to the highest phosphorus consumption observed in this medium (data not shown).

Astaxanthin productions were 5-6 times higher in saccharified than in non-saccharified media (Fig. 3; Table 3), reaching 26.0 in PSM and $22.5 \mathrm{mg} / \mathrm{L}$ in PSMS, respectively (Table 3). The improved astaxanthin production in mussel medium confirms a high $\mathrm{C} / \mathrm{N}$ ratio promotes astaxanthin production, since this ratio was 35 in by-product formulated media and 6.3 in YPD (Table 1). Optimal productions in mussel by-product formulated media were higher than in Yucca broth containing date juice (60\% fructose and $40 \%$ glucose) and urea as carbon and nitrogen sources $(8.1 \mathrm{mg} / \mathrm{L})$ [32], and in wood acid hydrolysate rich in xylose $(10.4 \mathrm{mg} / \mathrm{L})$ [18]. Culture media yielding similar productions were corn fiber hydrolysate containing glucose, xylose, arabinose and galactose as carbon sources $(20 \mathrm{mg} / \mathrm{L})$ and corn-starch hydrolysate [16], and corn steep liquor as carbon and nitrogen sources $(25.3 \mathrm{mg} / \mathrm{L})$ [33]. Supplementation of partiallysaccharified mussel medium with salts and vitamins was found to increase the yields of astaxanthin production (Table 3) compared to non-supplemented medium (PSM).

These results then proved the suitability of mussel processing waste as a source for $X$. dendrorhous growth, although it needs saccharification for its use as a source of astaxanthin.

\section{Effects of the initial concentration of sugars on astaxanthin production}

High concentrations of glucose have been reported to reduce astaxanthin production rate [34]. An experiment followed where the effluent was saccharified with $\alpha$-amylase and glucoamylase. The joint action of these two enzymes has a synergic effect on the hydrolysis of glycogen, yielding glucose as the final product $[19,20]$. The conditions utilized in the present research provided indeed a high degree of hydrolysis (92\%), leading to an effluent containing $129.5 \mathrm{~g} / \mathrm{L}$ total sugars, $106 \mathrm{~g} / \mathrm{L}$ reducing sugars, and $11 \mathrm{~g} / \mathrm{L}$ protein.

Four nutritive broths were prepared by diluting the $\alpha$-amylase and glucoamylase saccharified effluent to provide initial glucose concentrations of $20,40,80$ and $100 \mathrm{~g} / \mathrm{L}$ (Table 1). Totally-saccharified media were added with salts and vitamins because in addition to improving 

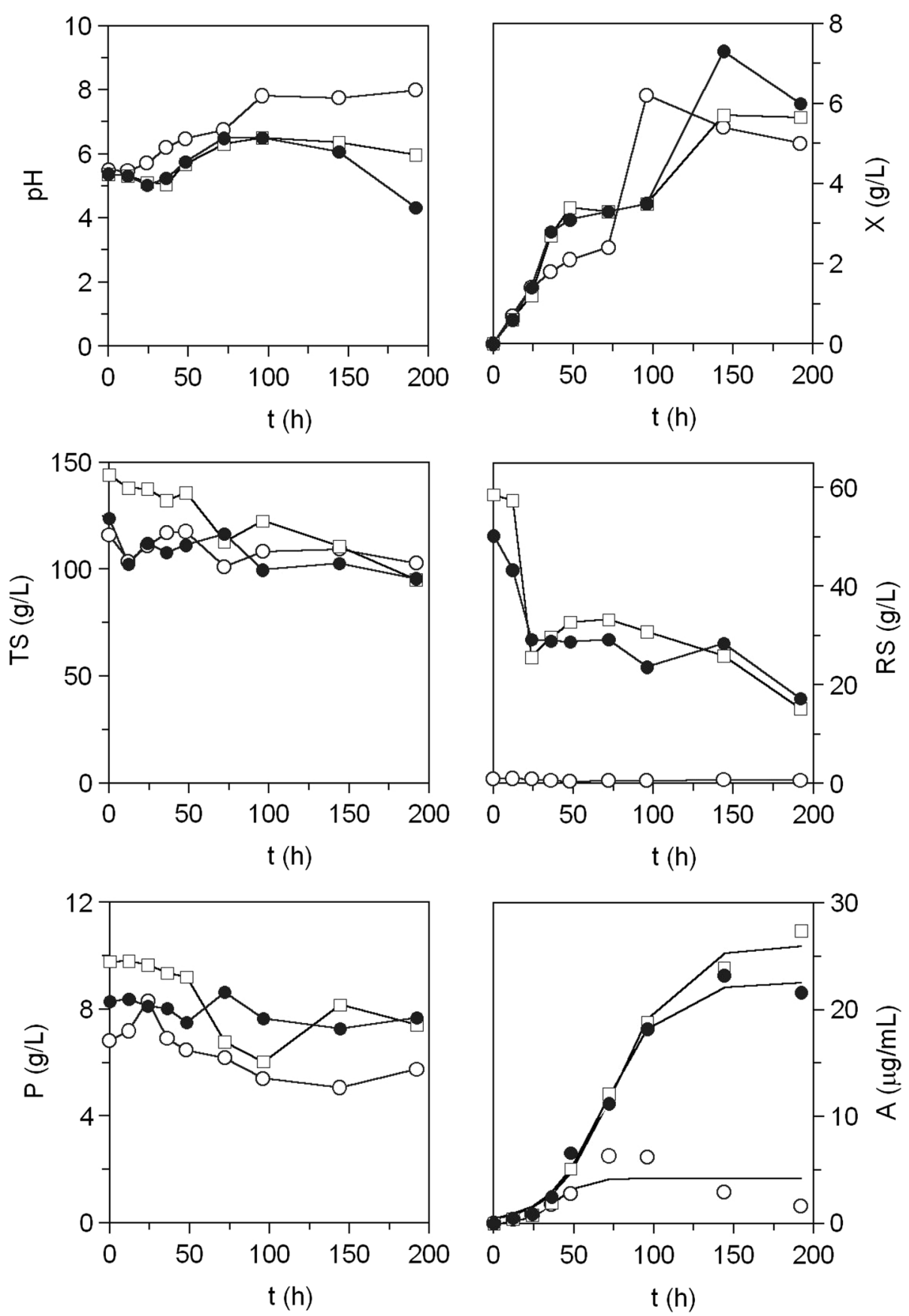

Fig. 3 Cultivations of X. dendrorhous ATCC 74219 in non-saccharified (MS) and partially-saccharified mussel waste (PSM and PSMS). Open circle MS, open square PSM, filled circle PSMS. X biomass, TS total sugars, A astaxanthin, RS reducing sugars, $P$ lowry-protein. Experimental data of astaxanthin are fitted to Eq. 2 (continuous line)

the yields of astaxanthin production, media supplementation was found to inhibit the slight cell lysis observed in non-supplemented medium (PSM).

Compared to partially-saccharified media, no diauxic growth profiles were observed (Fig. 5). Maximal cell concentrations increased and maximum growth rates decreased with increasing glucose initial concentration (Table 4), following previously published results [34]. On the other hand, maximal astaxanthin productions were tenfold lower in culture medium containing $100 \mathrm{~g} / \mathrm{L}$ glucose compared to $20 \mathrm{~g} / \mathrm{L}$ initial sugar content (Table 4). Those differences are in agreement with the 


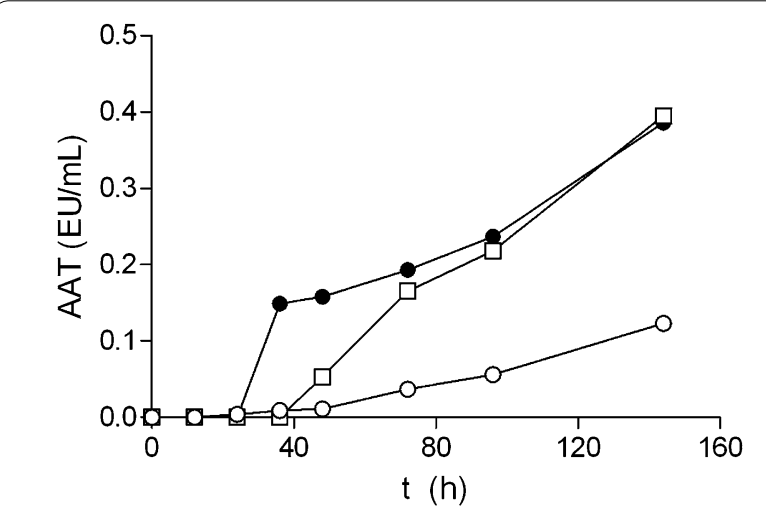

Fig. 4 Amylolytic activity (EU/mL) of X. dendrorhous ATCC 74219 cultures grown in non-saccharified (MS) and partially-saccharified mussel waste (PSM and PSMS). Open circle MS, open square PSM, filled circle PSMS

marked decrease in the yields of astaxanthin production to biomass with increasing initial sugar content (Table 4). These results confirm previous findings where $X$. dendrorhous undergoes Crabtree effect and other inhibitory effects derived from the high concentrations of glucose, and so high levels of oxygen are necessary to maintain high astaxanthin productivity [34]. The Crabtree effect consisted of glucose degradation proceeding partially via aerobic fermentation at high glucose concentrations and was previously reported for P. rhodozyma [28].

\section{Methods}

\section{Microorganisms}

We used two wild-type $X$. dendrorhous strains CECT1690 and CECT11028 from the Spanish Type Culture Collection, and a recombinant strain from the American Type Culture Collection, ATCC 74219. Stock cultures were frozen stocks at $-80{ }^{\circ} \mathrm{C}$ in Yeast Peptone Dextrose (YPD) broth containing $25 \%$ (v/v) glycerol.

\section{Culture media}

The screening of astaxanthin producer strains was carried out using two synthetic media, yeast peptone dextrose (YPD) and yeast complete medium (YCM). Astaxanthin production by $X$. dendrorhous was tested in four culture broths formulated using mussel-processing wastewater (MPW, Table 1). Proteins were removed by precipitation after acidification of MPW to a $\mathrm{pH} 4.0-4.5$ and then followed by MPW concentration using $100 \mathrm{kDa}$ ultrafiltration as previously described in detail [31]. The initial composition of concentrated MPW (CMPW) was: $4.22 \pm 0.03 \mathrm{~g} / \mathrm{L}$ of Lowry protein, $137 \pm 7.69 \mathrm{~g} / \mathrm{L}$ of total sugars and $0.69 \pm<0.01 \mathrm{~g} / \mathrm{L}$ reducing sugars. CMPW was partially-saccharified with $\alpha$-amylase from Aspergillus oryzae (Sigma-Aldrich, St. Louis, MO). Total saccharification was performed by sequential addition of glucoamylase from Aspergillus niger (AMG 300L; Novozyme Nordisk, Bagsvaerd, Denmark) to the partially-saccharified reaction mixture [19]. Hydrolysis were carried out at a controlled temperature $\left(45^{\circ} \mathrm{C}\right)$ in a thermostatized bath under orbital agitation (100 rpm) for 18 and $24 \mathrm{~h}$, respectively. The enzyme/substrate ratio was $3.5 \mathrm{U} / \mathrm{mL}$ for $\alpha$-amylase and $0.3 \mathrm{U} / \mathrm{mL}$ for glucoamylase. The progress of the enzymatic reaction was assessed according to the degree of hydrolysis $(\mathrm{H})$, expressed in percentage, defined as the ratio of reducing sugars (RS) in the supernatant and total sugars (TS) in the concentrated mussel effluent. According to this definition, $100 \%$ hydrolysis corresponds with total conversion of glycogen to glucose [19]. Following hydrolysis, samples were centrifuged $(12,000 \mathrm{~g}, 15 \mathrm{~min})$ and the supernatants recovered for analytical determinations and culture broth preparation. Table 1 shows the composition of the culture media. Yeast extract was from Cultimed (Panreac Química, Spain), and all salts and vitamins were analytical grade and purchased from Sigma-Aldrich (St. Louis, MO). All culture media were sterilized at $105^{\circ} \mathrm{C}$ for $30 \mathrm{~min}$.

\section{Culture conditions}

Cell suspensions in sterile distilled water were adjusted, after a previous calibration between $700 \mathrm{~nm}$ OD measurement and direct haemocytometric counting, so that the initial populations of the cultures were $2 \times 10^{6}$ cell/ $\mathrm{mL}$ in each flask [31].

Table 3 Fitting parameters of astaxanthin production to Eq. (2) in non-saccharified (MS) and partially-saccharified mussel waste (PSM and PSMS)

\begin{tabular}{|c|c|c|c|c|c|c|}
\hline Media & $A_{m}(\mathrm{mg} / \mathrm{L})$ & $v_{m}(\mathrm{mg} / \mathrm{L} \mathrm{h})$ & $\lambda_{a}(\mathrm{~h})$ & $Y_{A / X}(\mathrm{mg} / \mathrm{g})$ & $Y_{A / T S}(\mathrm{mg} / \mathrm{g})$ & $Y_{X / T S}(\mathrm{~g} / \mathrm{g})$ \\
\hline MS & 4.18 (NS) & 0.126 (NS) & 21.77 (NS) & 0.320 & 0.122 & 0.381 \\
\hline PSM & $26.00 \pm 1.98$ & $0.345 \pm 0.082$ & $38.98 \pm 9.09$ & 2.256 & 0.558 & 0.115 \\
\hline PSMS & $22.50 \pm 1.79$ & $0.313 \pm 0.078$ & $34.15 \pm 9.26$ & 3.565 & 0.653 & 0.215 \\
\hline
\end{tabular}

Yields of $X$. dendrorhous ATCC 74219 cultivation in MS, PSM and PSMS are also shown

$Y_{A / X}$ yield of astaxanthin production on biomass, $Y_{A / T S}$ yield of astaxanthin production on sugars consumed, $Y_{X / T S}$ yield of biomass on sugars consumed, NS non significant 

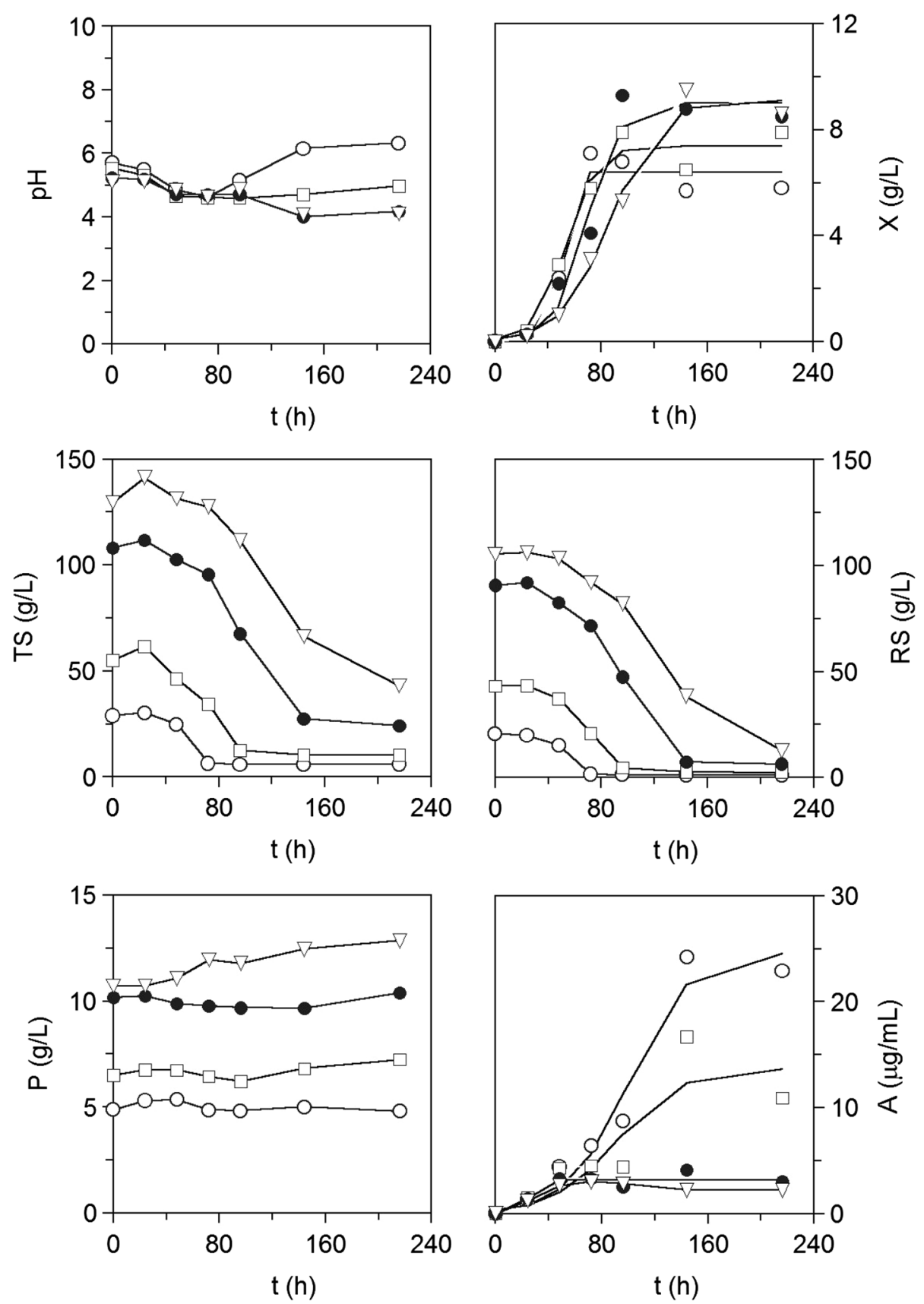

Fig. 5 Cultivation of $X$. dendrorhous ATCC 74219 in totally-saccharified mussel waste (TSMS) containing different initial concentration of sugars. Open circle $20 \mathrm{~g} / \mathrm{L}$, open square $40 \mathrm{~g} / \mathrm{L}$, filled circle $80 \mathrm{~g} / \mathrm{L}$, inverted triangle $100 \mathrm{~g} / \mathrm{L}$. X biomass, TS total sugars, $A$ astaxanthin, $R S$ reducing sugars, $P$ lowry-protein. Experimental data of astaxanthin and biomass are fitted to Eq. 2 (continuous line)

Submerged fermentations were carried out in $250 \mathrm{~mL}$ Erlenmeyer flasks containing $50 \mathrm{~mL}$ of production medium, being each flask an experimental unit for a defined incubation time. The experiments were carried out at $22{ }^{\circ} \mathrm{C}, 300 \mathrm{rpm}$ orbital agitation and illumination with Sylvania F30W/GRO lamps (Allied Electronics, Inc., USA) for 6-9 days.

\section{Sampling and analytical methods}

At pre-determined times, each experimental unit was centrifuged $(3500 \mathrm{~g}, 20 \mathrm{~min})$. Total sugars, reducing sugars and protein were measured in the supernatant. The pellet was washed twice, resuspended in distilled water and divided into two aliquots. One aliquot was used for quantifying biomass by appropriate diluting and measuring 
Table 4 Fitting parameters of biomass and astaxanthin production to Eq. (2) in totally-saccharified mussel waste (TSMS) containing different initial concentration of sugars

\begin{tabular}{|c|c|c|c|c|}
\hline & \multicolumn{4}{|l|}{ Biomass } \\
\hline & $X_{m}(\mathrm{~g} / \mathrm{L})$ & $v_{m}(g / L h)$ & $\lambda_{X}(\mathrm{~h})$ & $Y_{A / X}(\mathrm{mg} / \mathrm{g})$ \\
\hline $20 \mathrm{~g} / \mathrm{L}$ & $6.35 \pm 1.03$ & 0.977 (NS) & 45.61 (NS) & 3.962 \\
\hline $40 \mathrm{~g} / \mathrm{L}$ & $7.41 \pm 1.08$ & $0.159 \pm 0.119$ & $30.78 \pm 19.05$ & 1.389 \\
\hline $80 \mathrm{~g} / \mathrm{L}$ & $9.03 \pm 1.74$ & $0.185 \pm 0.168$ & $45.12 \pm 24.91$ & 0.355 \\
\hline \multirow[t]{3}{*}{$100 \mathrm{~g} / \mathrm{L}$} & $9.14 \pm 1.16$ & $0.126 \pm 0.060$ & $50.77 \pm 17.46$ & 0.261 \\
\hline & \multicolumn{4}{|l|}{ Astaxanthin } \\
\hline & $A_{m}(\mathrm{mg} / \mathrm{L})$ & $v_{m}(\mathrm{mg} / \mathrm{Lh})$ & $\lambda_{a}(\mathrm{~h})$ & $Y_{A / T S}(\mathrm{mg} / \mathrm{g})$ \\
\hline $20 \mathrm{~g} / \mathrm{L}$ & $24.64 \pm 6.53$ & $0.272 \pm 0.208$ & $54.58 \pm 32.25$ & 1.001 \\
\hline $40 \mathrm{~g} / \mathrm{L}$ & $13.71 \pm 8.72$ & 0.142 (NS) & 42.96 (NS) & 0.268 \\
\hline $80 \mathrm{~g} / \mathrm{L}$ & $3.24 \pm 0.80$ & 0.419 (NS) & 20.77 (NS) & 0.036 \\
\hline $100 \mathrm{~g} / \mathrm{L}$ & $2.58 \pm 0.47$ & 0.308 (NS) & 20.18 (NS) & 0.024 \\
\hline
\end{tabular}

Also yields of astaxanthin on biomass produced $\left(Y_{A / X}\right)$ and on total sugars consumed $\left(Y_{A / T S}\right)$ are shown

NS non significant

the $\mathrm{OD}$ at $700 \mathrm{~nm}$. After washing, biomass was dried at $105{ }^{\circ} \mathrm{C}$ and the dry weight calculated using a calibration curve. The other aliquot was used for astaxanthin extraction as described below. Total sugars (TS) were measured according to the phenol-sulfuric method of Dubois et al. [35], reducing sugars (RS) were determined by the 3,5-dinitrosalicylic acid (DNS) reaction [36] using glucose as standard, and protein using the method of Lowry [37]. Amylolytic activity (AAT) was measured using $4 \%$ $(\mathrm{w} / \mathrm{v})$ starch solutions as the substrate, and expressed in enzymatic units (EU) as described by Murado et al. [31]. All analytical determinations were made in duplicate.

\section{Cell disruption methods}

Chemical, mechanical and enzymatic cell disruption methods based on previously published works $[29,30]$ were applied to the extraction of astaxanthin from $X$. dendrorhous grown in YPD for $72 \mathrm{~h}$. Biomass $(4 \mathrm{~mL})$ was centrifuged $(12,000 \mathrm{~g}, 15 \mathrm{~min})$ and cells disrupted using different pre-treatments described below in detail. Cell disruption assays were carried out in duplicate from biomass before and after drying in a desiccator under vacuum at ambient temperature for $24 \mathrm{~h}$.

\section{Chemical cell disruption with dimethyl sulfoxide (DMSO)}

Biomass was treated with 1 (DMSO) or $2 \mathrm{~mL}(2 \times \mathrm{DMSO})$ preheated DMSO $\left(55^{\circ} \mathrm{C}\right)$ and vortex agitated for $30 \mathrm{~s}$. Samples were sonicated (4 cycles of $5 \mathrm{~min}$; P Selecta Ultrasons, Selecta S.A., Barcelona, Spain) avoiding overheating and pigment damage by cooling the sample between cycles in an ice-water bath.

\section{Chemical cell disruption under acidic conditions}

$X$. dendrorhous cells were resuspended in $4 \mathrm{~mL} 0.5 \mathrm{M}$ $\mathrm{HCl}$ and autoclaved at $121{ }^{\circ} \mathrm{C}$ for $5 \mathrm{~min}$. Samples were cooled to ambient temperature prior to astaxantin extraction.

\section{Mechanical cell disruption using glass beads}

Biomass was weighed and suspended in $2 \mathrm{~mL} 0.1 \mathrm{M}$ phosphate buffer $\mathrm{pH}$ 7.0. Identical weight of acid-washed glass beads 425-600 $\mu \mathrm{m}$ (30-40 U.S. sieve; Sigma-Aldrich, St. Louis, MO) was added and vortex (Reax Top Vortex Mixer, Heidolph, Instruments GmbH \& Co., Germany) mixed for $10 \mathrm{~min}$.

\section{Enzymatic cell disruption}

Cells were resuspended in $2 \mathrm{~mL} 0.1 \mathrm{M}$ phosphate buffer pH 7.0 and alcalase 2.4 L (Novozyme Nordisk, Bagsvaerd, Denmark) was added at a ratio of $0.01: 1(\mathrm{U} / \mathrm{mL})$ enzyme/ substrate. A solution of $10 \%$ SDS was added, and proteolysis was carried out in a water bath with soft agitation at $40{ }^{\circ} \mathrm{C}$ for $60 \mathrm{~min}$.

\section{Astaxanthin extraction}

Astaxanthin was extracted by adding $2 \mathrm{~mL}$ of a mixture hexane:ethylacetate (1:1) and $0.01 \mathrm{M}$ phosphate buffer $\mathrm{pH}$ 7.0, agitated for $30 \mathrm{~s}$ and separated by centrifugation $(3500 \mathrm{~g}, 5 \mathrm{~min})$. The pigmented organic phase from the supernatant was recovered and the astaxanthin measured spectrophotometrically (PerkinElmer ${ }^{\circledR}$ Lambda $25 \mathrm{UV} / \mathrm{Vis}$ spectrophotometer, PerkinElmer Inc., Massachusetts, USA) at the $\lambda \max (480 \mathrm{~nm}$ : A480). The 
spectrophotometric measurement at this wavelength is due to astaxanthin and other carotenoids. Nonetheless, $X$. dendrorhous contains astaxanthin as its main (>85\%) pigment [38], being over-produced in the geneticallymodified strain ATCC 74219 [27]. Therefore, A480 here reported is mainly due to astaxanthin. Extractions were repeated twice, and pigment recovery calculated as follows [30]:

$$
Y=\frac{A_{480} \times V_{H x: E t A c} \times 10^{6}}{100 \times V_{c} \times E_{1 \%}}
$$

where $Y$ is the astaxanthin per volume of culture $(\mathrm{mg} / \mathrm{L})$; $V_{H x: E t A c}$ is the volume of extracting solvent; $V_{c}$ the volume of culture and $E_{1 \%}$ the specific extinction coefficient.

\section{Mathematical models}

A logistic equation fitted the kinetics of biomass and astaxanthin production by $X$. dendrorhous [39]:

$$
P=\frac{P_{m}}{1+\exp \left[2+\frac{4 v_{m}}{P_{m}}\left(\lambda_{p}-t\right)\right]}
$$

where $P$ is the biomass or astaxanthin production $(\mathrm{mg} / \mathrm{L})$; $t$ is the time of culture (h); $P_{m}$ is the maximum biomass or astaxanthin production $(\mathrm{mg} / \mathrm{L}) ; v_{m}$ is the maximum rate of biomass or astaxanthin production $(\mathrm{mg} / \mathrm{L} \mathrm{h})$, and $\lambda_{P}$ is the delay in biomass or astaxanthin production (h).

\section{Numerical methods}

Fitting procedures and parametric estimations were carried out by minimizing the sum of quadratic differences between observed and model-predicted values using the nonlinear least-squares (quasi-Newton) method provided by the Solver macro of the Microsoft Excel 2007 spreadsheet (Microsoft, Redmond, WA).

The yields of astaxanthin production on biomass $\left(Y_{A / X}\right)$ and sugars consumed $\left(Y_{A / T S}\right)$ were calculated by dividing the maximum values of astaxanthin production $(\mathrm{mg} / \mathrm{L})$ by the biomass $(\mathrm{g} / \mathrm{L})$ and total sugar consumption $(\mathrm{g} / \mathrm{L})$, respectively. Also, the yield of biomass on sugars consumed $\left(Y_{X / T S}\right)$ was calculated to compare the performance of the three strains of $X$. dendrorhous in YPD and YCM.

\begin{abstract}
Abbreviations
AAT: amylolytic activity; CMPW: concentrated mussel processing wastewater; DMSO: dimethylsulfoxide; EU: enzymatic units; $\mathrm{H}$ : degree of hydrolysis; MPW: mussel processing wastewater; MS: mussel-processing waste medium supplemented with salts and vitamins; PSMS: partially-saccharified mussel-processing waste medium supplemented with salts and vitamins; RS: reducing sugars; TS: total sugars; YCM: yeast complex medium; YPD: yeast potato dextrose.
\end{abstract}

\section{Authors' contributions}

IRA designed and performed the experiments, analyzed and interpreted the data and wrote the manuscript. JAV supervised the research, worked on the mathematical modelling and edited all figures and tables. Both authors read and approved the manuscript.

\section{Author details}

${ }^{1}$ Grupo de Reciclado y Valorización de Residuos (REVAL), Instituto de Investigacións Mariñas (IIM-CSIC), R/Eduardo Cabello 6, 36208 Vigo, Spain. ${ }^{2}$ Departamento de Química Analítica y Alimentaria, Facultad de Ciencias de Ourense, Universidad de Vigo, Campus As Lagoas s/n, Orense, Spain.

\section{Acknowledgements}

This research was financially supported by "Contrato Programa CSIC-Xunta de Galicia 2015". We wish to thank Ana Durán and Margarita Nogueira for their excellent technical assistance. We are grateful to Ramiro Martinez (Novozymes $\mathrm{A} / \mathrm{S}$, Spain) for supplying the glucoamylase utilized in this work.

\section{Competing interests}

The authors declare they have no competing interests.

Received: 15 July 2015 Accepted: 30 October 2015

Published online: 09 November 2015

\section{References}

1. Mata-Gómez LC, Montáñez JC, Méndez-Zavala AA, Aguilar CN. Biotechnological production of carotenoids by yeasts: an overview. Microb Cell Fact. 2014;13:1-11.

2. Barros MP, Poppe SC, Souza-Junior TP. Putative benefits of microalgal astaxanthin on exercise and human health. Braz J Pharmacog. 2011;21:283-9.

3. Yoshida H, Yanai H, Ito K, Tomono Y, Koikeda T, Tsukahara H, et al. Administration of natural astaxanthin increases serum $\mathrm{HDL}$-cholesterol and adiponectin in subjects with mild hyperlipidemia. Atherosclerosis. 2010;209:520-3.

4. Park JS, Chyun JH, Kim YK, Line LL, Chew BP. Astaxanthin decreased oxidative stress and inflammation and enhanced immune response in humans. Nutr Metab. 2010;7:18.

5. Ambati RR, Moi PH, Ravi S, Aswathanarayana RG. Astaxanthin: sources, extraction, stability, biological activities and its commercial applications. A Review. Mar Drugs. 2014;12:128-52.

6. Del Campo JA, García-González M. Outdoor cultivation of microalgae for carotenoid production: current state and perspectives. Appl Microbiol Biotechnol. 2007;74:1163-74.

7. Handayani AD, Sutrisno I, Indraswati N, Ismadji S. Extraction of astaxanthin from giant tiger (Panaeus monodon) shrimp waste using palm oil: studies of extraction kinetics and thermodynamic. Bioresour Technol. 2008;99:4414-9.

8. Chen $\mathrm{H}$, Meyers SP. Extraction of astaxanthin plgment from crawfish waste using a soy oil process. J Food Sci. 1982;47:892-6.

9. Amado IR, Váquez JA, Murado MA, González MP. Recovery of astaxanthin from shrimp cooking wastewater: optimization of astaxanthin extraction by response surface methodology and kinetic studies. Food Bioproc Technol. 2014;8:371-81.

10. Amado IR, González MP, Murado MA, Vázquez JA. Shrimp (Penaueus vannamei) cooking wastewater as a source of astaxanthin and bioactive peptides. J Chem Technol Biotechnol. 2015;. doi:10.1002/jctb.4647.

11. Chávez-Cabrera C, Flores-Bustamante ZR, Marsch R, Montes MC, Sánchez S, Cancino-Díaz JC, et al. ATP-citrate lyase activity and carotenoid production in batch cultures of Phaffia rhodozyma under nitrogen-limited and nonlimited conditions. Appl Microbiol Biotechnol. 2010;85:1953-60.

12. Guerin M, Huntley M, Olaizola M. Haematococcus astaxanthin: applications for human health an nutrition. Trends Biotechnol. 2003;21:210-6.

13. Lorenz RT, Cysewski GR. Commercial potential for Haematococcus microalgae as a natural source of astaxanthin. Trends Biotechnol. 2000;18:160-7.

14. Bumbak F, Cook S, Zachleder V, Hauser S, Kovar K. Best practices in heterotrophic high-cell-density microalgal processes: achievements, potential and possible limitations. Appl Microbiol Biotechnol. 2011;91:31-46.

15. Fontana JD, Mitchell DA, Molina OE, Gaitan A, Bonfim TMB, Adelmann J, et al. Starch depolymerization with diluted phosphoric acid and application of the hydrolysate in astaxanthin fermentation. Food Technol Biotechnol. 2008:46:305-10. 
16. Nghiem NP, Montanti J, Johnston D. Production of astaxanthin from corn fiber as a value-added co-product of fuel ethanol fermentation. Appl Biochem Biotechnol. 2009;154:48-58.

17. An G-H, Jang B-G, Cho M-H. Cultivation of the carotenoid-hyperproducing mutant 2A2N of the red yeast Xanthophyllomyces dendrorhous (Phaffia rhodozyma) with molasses. J Biosci Bioeng. 2001;92:121-5

18. Parajó J, Santos V, Vázquez M. Production of carotenoids by Phaffia rhodozyma growing on media made from hemicellulosic hydrolysates of Eucalyptus globulus wood. Biotechnol Bioeng. 1998;59:501-6.

19. Pastrana LM, González M, Murado MA. Production of gibberellic acid from mussel processing wastes in submerged batch culture. Biores Technol. 1993;45:213-21.

20. Torrado A, González MP, Murado MA. pH regulation in solid state culture through the initial ratio between oxidized and reduced sources of nitrogen. A model applicable to the amylase production by Aspergillus oryzae. Biotechnol Tech. 1998;12:411-5.

21. Vázquez JA, González MP, Murado MA. Pediocin production by Pediococcus acidilactici in solid state culture on a waste medium. Process simulation and experimental results. Biotechnol Bioeng. 2004;85:676-82.

22. Vázquez JA, Montemayor M, Fraguas J, Murado M. Hyaluronic acid production by Streptococcus zooepidemicus in marine by-products media from mussel processing wastewaters and tuna peptone viscera. Microbial Cell Fact. 2010;9:46.

23. Díaz A, Sieiro C, Villa TG. Production and partial characterization of $\beta$-amylase by Xanthophyllomyces dendrorhous. Lett Appl Microbiol. 2003;36:203-7.

24. Marín D, Linde D, Lobato MF. Purification and biochemical characterization of an a-glucosidase from Xanthophyllomyces dendrorhous. Yeast. 2006;23:117-25

25. Fernández-Arrojo L, Marín D, Gómez De Segura A, Linde D, Alcalde M, Gutiérrez-Alonso P, et al. Transformation of maltose into prebiotic isomaltooligosaccharides by a novel a-glucosidase from Xantophyllomyces dendrorhous. Proc Biochem. 2007;42:1530-6.

26. De La Fuente JL, Rodríguez-Saíz M, Schleissner C, Díez B, Peiro E, Barredo J. High-titer production of astaxanthin by the semi-industrial fermentation of Xanthophyllomyces dendrorhous. J Biotechnol. 2010;148:144-6.

27. Jacobson GK, Jolly SO, Sedmak JJ, Skatrud TJ, Wasileski JM. Astaxanthin over-producing strains of Phaffia rhodozyma. Method for their cultivation and their use in animal feeds. 2000. Archer-Daniels-Midland Company. United States. Patent number 6.015.684.
28. Reynders M, Rawlings D, Harrison S. Studies on the growth, modeling and pigment production by the yeast Phaffia rhodozyma during fed-batch cultivation. Biotechnol Lett. 1996;18:649-54.

29. Da Fonseca RAS, Rafael RS, Kalil SJ, Burkert CAV, Burkert JFM. Different cell disruption methods for astaxanthin recovery by Phaffia rhodozyma. Afr J Biotechnol. 2011;10:1165-71.

30. Sedmak JJ, Weerasinghe D, Jolly S. Extraction and quantitation of astaxanthin from Phaffia rhodozyma. Biotechnol Tech. 1990;4:107-12.

31. Murado MA, Siso MIG, González MP, Montemayor MI, Pastrana L, Pintado J. Characterization of microbial biomasses and amylolytic preparations obtained from mussel processing waste treatment. Bioresour Technol. 1993;43:117-25

32. Ramírez J, Obledo N, Arellano M, Herrera E. Astaxanthin production by Phaffia rhodozyma in a fed-batch culture using a low cost medium feeding. E-Gnosis. 2006:4:1-9.

33. Kesava S, An G, Kim C, Rhee S, Choi E. An industrial medium for improved production of carotenoids from a mutant strain of Phaffia rhodozyma. Bioprocess Biosyst Eng. 1998;19:165-70.

34. Yamane Y, Higashida K, Nakashimada Y, Kakizono T, Nishio N. Influence of oxygen and glucose on primary metabolism and astaxanthin production by Phaffia rhodozyma in batch and fed-batch cultures: kinetic and stoichiometric analysis. Appl Environ Microbiol. 1997;63:4471-8.

35. Dubois M, Gilles K, Hamilton J, Rebers P, Smith F. Colorimetric method for determination of sugars and related substances. Anal Chem. 1956;28:350-6.

36. Bernfeld P. Enzymes of starch degradation and synthesis. Adv Enzymol. 1951;12:379-427.

37. Lowry OH, Rosebrough NJ, Farr AL, Randall RJ. Protein measurement with the folin phenol reagent. J Biol Chem. 1951;193:265-75. 38.

38. Andrewes AG, Phaff HJ, Starr MP. Carotenoids of Phaffia rhodozhyma, a red pigmented fermenting yeast. Phytochemistry. 1976;15:1003-7.

39. Vázquez JA, Murado MA. Mathematical tools for objective comparison of microbial cultures. Application to evaluation of 15 peptones for lactic acid bacteria productions. Biochem Eng J. 2008;39:276-87.

\section{Submit your next manuscript to BioMed Central and take full advantage of:}

- Convenient online submission

- Thorough peer review

- No space constraints or color figure charges

- Immediate publication on acceptance

- Inclusion in PubMed, CAS, Scopus and Google Scholar

- Research which is freely available for redistribution

Submit your manuscript at 